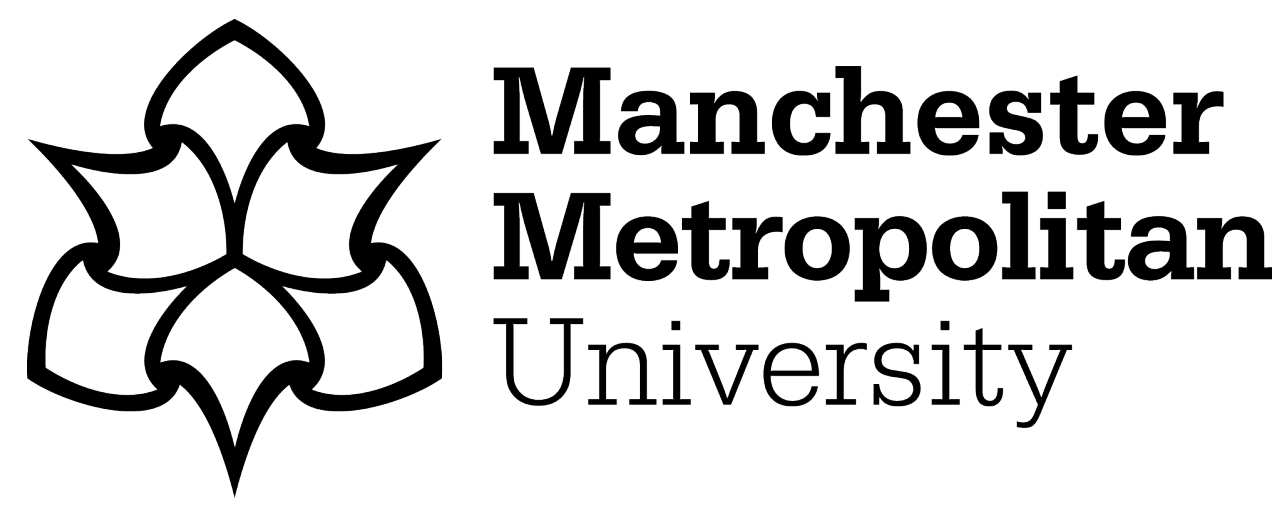

Barn, R and Tan, JP (2015) Foster youth and drug use: Exploring risk and protective factors. Children and Youth Services Review, 56. pp. 107-115. ISSN 0190-7409

Downloaded from: https://e-space.mmu.ac.uk/621309/

Version: Accepted Version

Publisher: Elsevier

DOI: https://doi.org/10.1016/j.childyouth.2015.07.007

Please cite the published version 


\title{
Foster youth and drug use: Exploring risk and protective factors
}

\author{
Ravinder Barn ${ }^{\mathrm{a}}$, \\ r.barn@rhul.ac.uk \\ Jo-Pei Tan ${ }^{\mathrm{b}}$ \\ j.tan@mmu.ac.uk
}

a School of Law, Royal Holloway University of London, Egham, Surrey TW20 0EX, United Kingdom

${ }^{\mathbf{b}}$ Department of Social Care \& Social Work, Manchester Metropolitan University, Birley Fields Campus, 53 Bonsall Street, Manchester M15 6GX, United Kingdom

\begin{abstract}
Substance use and misuse experiences of foster youth remain an under-researched area. Given that early use of drugs is said to be a common factor among $90 \%$ of those who develop substance misuse problems in their lifetime, this is an important area of academic study (Dennis, White, \& Ives, 2009). By drawing upon primary empirical data from a mixed-methods study, this paper addresses an important gap in the literature and seeks to provide an improved understanding of foster youth, drug use and vulnerability. A total of 261 foster youth, who had exited care, contributed to a quantitative survey, and a further 35 provided qualitative narratives of their lived experience. Key risk factors including experience of homelessness, school exclusion and living setting are identified as strong influences that predict high levels of drug use among foster youth. Targeted social support and interventions in the form of pre-leaving care in the context of a strong practitioner/youth relationship are suggested to help ameliorate poor outcomes to obviate the problem of substance misuse among foster youth.
\end{abstract}

Keywords

Foster youth, Drug use, Disadvantage, Risk, Protective factors

\section{Introduction}

Youth leaving foster care face numerous and serious challenges in the process of transition. The negative experiences of instability among young people in and leaving care point to a range of severe disadvantage including housing, education and employment (Broad, 1998, Biehal et al., 1995, Wade, 2003, Barn et al., 2005, Courtney et al., 2011). Moreover, studies in Australia, USA, Spain and the UK have not only consistently documented a higher likelihood of risky behaviour among this vulnerable population (Barth, 1990, Barn and Mantovani, 2007, Barn and Tan, 2012, Chase et al., 2006, Ward et al., 2003) but also a problematic association between foster care, drug use and young people (Mendes and 
Moslehuddin, 2006, Del Valle et al., 2009, Allen, 2003, Braciszewski et al., 2014). Thus, drug use which may become problematic is deemed to be yet another challenge among foster youth.

Although generalisations are often made about the high number of people with a care history among samples of drug users, understanding of drug use and foster care remains patchy. On the whole, many past studies have focused on prevalence and concluded that there are higher rates of drug use among foster youth than their peers in the general population (Jackson and Simon, 2005, McCrystal et al., 2008, Vaughn et al., 2007, Ward et al., 2003). However, few studies have explored risks and protective factors specifically related to substance use/misuse and the care experience.

A U.S. longitudinal study found that poor quality foster care that included weak bonding, and a lack of supervision from caregivers were risk factors that resulted in increased drug use among young people in the care system (Cheng \& Lo, 2011). Interestingly, although this study hypothesised an association between pre-care child maltreatment (risk factor) and drug use, this was not confirmed in its findings. However, the influence of pre-care experiences and risky behaviours among this group has been identified elsewhere (Darker, Ward, \& Caulfield, 2008).

In a Canadian study, Guibord, Bell, Romano, and Rouillard (2011) found that while increasing age was associated with increased risk for drug use, protective factors that include perceived quality of youth-caregiver relationship appeared to protect youth against substance misuse. In particular, those who reported high caregiver monitoring were three times less likely to report moderate to high drug use compared with youth with lower caregiver monitoring (Masten and Reed, 2002, Wall and Kohl, 2007). Moreover, youth who reported greater problem-solving skills, positive emotion and behaviour regulation tended to demonstrate greater resilience when facing life adversity (Masten \& Reed, 2002) and were less physically aggressive (Legault, Anawati, \& Flynn, 2006). However, scholars have consistently noted that there is a lack of readily available services such as life-skill training or further education opportunities following young people's discharge from care and transition to adulthood (Stein, 2006). Thus, findings from these studies have demonstrated the significance of supportive networks, life-skill training and engaged relationship with a caregiver on reducing risk of drug misuse among vulnerable youth. 
A multitude of vulnerabilities related to young people's experience in foster care is often described in terms of risk factors. This includes the social and psychological impact of placement instability, poor education outcomes, homelessness and youth crime (Allen, 2003, Taylor, 2006, Barn and Tan, 2012, Wincup et al., 2003). These circumstances could expose former foster youth to significant adversities during transition to adulthood such as unemployment and poverty, which have strong correlations with substance misuse (Feng et al., 2013, Henkel, 2011, Wincup et al., 2003). Specifically, research has indicated that the stability of placements appears to be important for the development of foster youth in that greater stability (e.g., fewer placements, and good quality care) is associated with less drug use (Aarons et al., 2008). Arguably, the cumulative effects of these risk factors may lead to higher rates of substance misuse among foster youth. However, a study by Iglehart (1993) failed to detect relationship between placement stability and drug use among youth in foster care system. Thus, the issue of placement instability and drug involvement among young people in the care system remain an open question.

In terms of ethnicity, there is some research evidence to show that White youth tend to be more vulnerable to substance misuse as compared with youth of African background (Guibord et al., 2011, Wall and Kohl, 2007). Specifically, it was found that youth of African background from poor families and living in high crime neighbourhoods tend to adopt tighter curfews which often promote resilience (Jarrett, 1995). Moreover, resilient adults who were former foster youth also reported better well-being, less school expulsion and fewer problems with the juvenile justice system while in care (Hass \& Graydon, 2009). Youth living settings have been found to be linked to drug use activities. For example, in a study of over 400 older youth in foster care in Missouri, USA, Vaughn et al. (2007) reported that those in independent and congregate living settings were more likely to be using illicit substances. The nature of such settings (i.e. greater freedom, and behavioural issues/mental health) are said to generate their own risk factors that can contribute to high levels of substance use/misuse among youth in foster care (Havlicek, Garcia, \& Smith, 2013).

Research literature has highlighted the relationship between mental health functioning and substance misuse among young people, in particular those involved in the public child welfare system (Havlicek et al., 2013, Vaughn et al., 2007). The rates of substance misuse were not only particularly prevalent among foster youth who were diagnosed with behavioural and psychological difficulties such as conduct disorder and post-traumatic stress disorder (Vaughn 
et al., 2007), but mental health problems and emotional difficulties were also often found to precede alcohol and drug use problems (Aarons, Brown, Hough, Garland, \& Wood, 2001). Surprisingly, only a few studies have documented empirical evidence on the relationship between mental health status and substance misuse among youth in the public care system considering the relationship between increased period in out-of-home placement and prevalence of drug related problems (Guibord et al., 2011, Slesnick and Meade, 2001). Others have failed to establish a significant relationship between internalising problems (i.e. anxiety and depression) and drug involvement among young people (Helstrom et al., 2004, Stice et al., 2002). Thus, the relationship between mental well-being and drug related problems, particularly among foster youth, remains unclear.

Studies on this particular population of foster youth are especially important, as these young people are preparing both for transition to adulthood and exiting the foster care system, where support networks and professional assistance may not be as readily available (Vaughn et al., 2007, Aarons et al., 2001, Barn, 2010). Previous research has sought to focus on key indicators that may generate risk or resilience understandings to help promote effective practice in working with vulnerable foster youth. However, our understanding of foster youth, drug use, and risk and protective factors remains rather fragmented. Crucially, there is also a lack of research that examines, simultaneously, the contribution of risks and protective factors related to in/post care experiences on family support, professional assistance, life-skill development and well-being on predicting drug use among foster youth. Moreover, there is a dearth of a mixed-methods approach that captures understandings both quantitatively and qualitatively of this hard to reach group of vulnerable foster youth. This paper, therefore, seeks to make an important contribution to address this gap in our knowledge and understanding.

\section{Method}

Using a mixed-methods approach, this study sets out to explore the experiences and outcomes of young people transitioning from foster care to independence in six local authorities in England. A total of 261 young people who had left care participated in this study. The key focus of this paper is to understand the nature and extent of reported drug use among foster youth and the impact of in/post care experiences. 
A quantitative survey method and purposive sampling approach were used to obtain a good cross-representation sample to ensure a range of young people from different age groups, ethnic backgrounds and gender distribution. The self-administered questionnaire included demographic, and other key questions about in/post care experiences and nature and extent of drug use in previous 30 days. The focus on previous 30 days was considered to be important in measuring current/most recent drug use. Risk factors measured included placement disruption, that is, a move from one foster home to another ( $1=$ Once only to $4=10$ times or more), homelessness since leaving foster care $(1=$ No at all to $5=$ More than 1 year $)$, unemployment since leaving foster care $(1=$ Yes, $0=$ No), frequency of school exclusion during foster care, and current living situation $(1=$ Alone; $0=$ Shared with others $)$. Protective factors included completion of college education since leaving foster care $(1=$ Yes, $0=$ No), support from family members as indicated by a total score based on frequency of contact with mothers, fathers, siblings and other relatives $(0=$ Not at all to $2=$ Frequent $)$, support from social service professionals in care based on a total score on help/advice on education, drugs and alcohol, sexual relationships, contraception, health and other matters $(1=$ Yes, $0=$ No), and adequacy of preparation for transitions from foster care to independent living as indicated by a total score on assistance with budgeting skills, relationship concerns, career advice, housing, claiming benefits and cooking skills $(1=$ Yes, $0=$ No). Higher scores in family support, living skills and professional support indicates more support from family members, greater life skills/help provided prior to and after leaving care, and stronger professional support in care. The respondents were also asked to report on perceived good physical and emotional health $(1=$ Yes, $0=$ No). Questions on drug use were included in the survey where a list of legal drugs (i.e. alcohol and tobacco) and illegal drugs (i.e. cannabis, ecstasy, crack/cocaine, LSD, amphetamines, aerosol) was employed to record the nature and extent of foster youth's drug use in the past 30 days based on a 4-point Likert scale ranging from 0 (Never) to 4 (Almost daily). Higher total score in overall, legal and illegal drugs indicate more regular drug use among young people.

Predictive Analytics SoftWare (PASW) Statistics Version 18 was used in the quantitative data analysis. Hierarchical regression models were computed to predict the likelihood of the involvement of foster youth in self-reported drug use — both legal and illegal drug use as a function of various types of risks and protective factors. Predictor variables were entered sequentially in blocks into the regression model. The analysis begins by first regressing young people's involvement in drug use on the demographical characteristics (e.g. age, gender 
and ethnicity) as control variables. In the second step, the various types of risks (e.g. total placement, homelessness, unemployment, school exclusion and living status) were added to the models. After controlling for these factors, the final step added the range of positive stimuli, namely family support (during and after care), professional support in care, living skills (during and after care), college education and well-being status.

Young people who engaged in the completion of self-completion questionnaires were invited to participate in one-to-one interviews and focus group discussions (FGDs). Focus group discussions $(\mathrm{n}=8)$ that included 16 male and 22 female respondents and in-depth interviews $(n=18)$ were conducted to provide a narrative of the context of foster youth's experiences to help understand the quantitative findings. All interviews were conducted on a 1-1 basis, while FGDs were facilitated by two researchers. Social service agency locations served as the venue, and interviews/FGDs varied in duration from $45 \mathrm{~min}$ to $90 \mathrm{~min}$. Specifically, FGDs explored the generic experiences of foster youth in relation to their care and after care experiences including preparation for leaving foster care to live independently, education, housing, employment, and social support from family and social service professionals. Personal narratives were explored in 1-1 interviews which generally followed the FGDs. Engagement in drug use was a key area for discussion in both FGDs and interviews. With the consent of the respondents, the majority of the interviews/focus groups were digitally recorded and transcribed verbatim. The qualitative data analysis software, Atlas.ti, was used to assist with the thematic analysis and to code the key terms and analyse interview data with greater ease (Ritchie \& Spencer, 1994). The qualitative data themes have been grouped in two segments, risk and protection, to mirror the quantitative findings to help provide a focused and coherent discussion on the nature and extent of drug use among foster youth.

Key ethical considerations including confidentiality, anonymity, voluntary participation, informed consent, and secure data storage were observed throughout the process of research. The study adhered to the British Sociological Association ethical guidelines and ethical approval was obtained from the lead author's university research committee.

The profile of young people is presented in Table 1. The sample was $43.3 \%$ male and $56.7 \%$ female with a mean age of 18 years old. The numbers of young people who described their ethnicity as White were slightly more than half(55.6\%); while the rest reported a minority ethnic background (44.4\%). The latter includes those of bi-racial (15.3\%), Black-Caribbean (13.4\%), Black African (11.1\%), and Asian/Chinese/other ethnic groups (4.6\%). Fifty-five 
percent of young people were unemployed, followed by $32.3 \%$ who were employed and $12.5 \%$ who were at college (predominantly further education) at the time of the study. More than half (53.5\%) of the sampled young people were currently living alone while the rest lived with other people. Forty percent of them reported having been homeless at some point in their lives after they left care. The duration of such homelessness was said to persist from a few weeks to more than a year. Almost half (49\%) reported having been suspended from school in the past. Almost $40 \%$ reported that they had been in foster care for 10 or more years and about a quarter for three to five years. Over two-fifths $(41 \%)$ of the foster youth reported at least four placements during their stay in care, and $16.7 \%$ had experienced ten or more placements. About two-thirds of the foster youth obtained college education after leaving care and $77.6 \%$ reported good physical and emotional health status during time of the study. In terms of support networks, almost half of the group reported having received high levels of support from family members prior to $(50.9 \%)$ and after leaving care (42\%); and acquired a substantial amount of living skills prior to $(49.0 \%)$ and after leaving care $(49.8 \%)$. Less than half of the sample reported receiving low level of support from social service professionals while in care $(44.0 \%)$.

Table 1. Descriptive statistics of demographic characteristic, risk and protective factors $(n=261)$.

\begin{tabular}{|c|c|c|c|c|}
\hline Variable & n $(\%)$ & Mean & $\begin{array}{l}\text { Standard } \\
\text { deviation }\end{array}$ & Score range \\
\hline Male & $43.3 \%$ & & & \\
\hline \multicolumn{5}{|l|}{ Ethnicity } \\
\hline White & $55.6 \%$ & & & \\
\hline Black-Caribbean & $13.4 \%$ & & & \\
\hline Bi-racial & $15.3 \%$ & & & \\
\hline Other ethnicities & $15.7 \%$ & & & \\
\hline Age (years) & & 18.87 & 1.32 & $16-23$ \\
\hline $16-18$ & $40.4 \%$ & & & \\
\hline $19-20$ & $51.0 \%$ & & & \\
\hline $21-23$ & $8.6 \%$ & & & \\
\hline \multicolumn{5}{|l|}{ Risk factors } \\
\hline Unemployment & $55.1 \%$ & & & \\
\hline Living alone (yes) & $53.5 \%$ & & & \\
\hline Homelessness (yes) & & 0.68 & 1.13 & \\
\hline Total of placement (frequency) & & 2.42 & 0.96 & $1-4$ \\
\hline Once only & $16.7 \%$ & & & \\
\hline $2-4$ & $41.2 \%$ & & & \\
\hline $5-9$ & $25.3 \%$ & & & \\
\hline 10 or more & $16.7 \%$ & & & \\
\hline
\end{tabular}




\begin{tabular}{cllll}
\hline Variable & n $(\boldsymbol{\%})$ & Mean & $\begin{array}{l}\text { Standard } \\
\text { deviation }\end{array}$ & Score range \\
\hline School exclusion (frequency) & & 1.67 & 2.88 & $0-21$ \\
Never & $51.0 \%$ & & & \\
$1-2$ & $25.6 \%$ & & & \\
$3-4$ & $13.8 \%$ & & & \\
5 or more & $9.6 \%$ & &
\end{tabular}

Protective factors

$\begin{array}{lllll}\text { High family support (in-care) } & 50.9 \% & 4.87 & 2.78 & 0-12 \\ \text { High family support (after) } & 42.0 \% & 4.23 & 3.06 & 0-12 \\ \text { High living skills (in-care) } & 49.0 \% & 2.65 & 1.85 & 0-6 \\ \text { High living skills (after) } & 49.8 \% & 2.70 & 1.77 & 0-6 \\ \text { High professional support (in-care) } & 44.0 \% & 4.01 & 2.44 & 0-8 \\ \text { College education (yes) } & 66.7 \% & & & \\ \text { Self-perceived well-being } & 77.6 \% & & & \end{array}$

Note. Higher levels of family support, living skills and professional support refer to percentages of young people with a mean score of higher than the group mean.

Self-perceived well-being refers to percentage of young people who perceived good physical and emotional well-being at the time of study.

\section{Results}

\subsection{Survey findings}

\subsubsection{Self-reported drug use}

Almost half of the young people had been experimenting with illegal drugs on a regular basis (either 'sometimes', 'often' or 'almost daily') at some stage in their lives while a large number of them reported regular alcohol and tobacco use. Specifically, almost $90 \%$ of the young people reported legal drug use and, about $40 \%$ reported illegal drug use within the past 30 days. Overall, young people in foster care who had experimented with legal or illegal drugs in their lifetime also indicated a higher extent of legal drug use $(\mathrm{M}=2.74, \mathrm{SD}=1.87)$ as compared with illegal drug experimentation $(\mathrm{M}=1.18, \mathrm{SD}=1.68)$ (see Table 2$)$. In the UK, illegal drugs are categorised according to their potential for harm in the 1971 Misuse of Drugs Acts. The severity of harm is considered to be greatest in Class A drugs and the associated criminal penalty is also the greatest here (Monaghan, 2014). Our findings show that the use of legal substances (i.e. alcohol \& cigarettes) was largest $(<70 \%)$; while use of Class B drugs (for example, cannabis) was slightly over $45 \%$ and Class A drugs (for example, ecstasy, heroin, crack/cocaine, LSD, amphetamines, aerosol) was lowest ranging between $1.7 \%$ and $14.4 \%$ 
within the last 30 days (see Table 2). As shown in Table 3, there was no significant difference in the overall drug use and in the use of legal and illegal drugs between males and females. Young people of White ethnicity, however, were found to report higher levels of drug use in terms of overall drug use $(\mathrm{t}=3.33 ; \mathrm{p}<0.001)$, legal drug use $(\mathrm{t}=3.04 ; \mathrm{p}<0.01)$ and illegal drug use $(t=2.88 ; p<0.01)$ as compared with those of bi-racial, Black-Caribbean and other ethnic backgrounds (see Table 3). In addition, younger foster youth were found to report higher levels of illegal drug use compared with older youth $(t=6.86, p<0.01)$ (Table 3$)$.

Table 2. Types of drug and frequency of use. Note: Score range legal substance use is 0 to 6, illegal substance use is 0 to 9 and overall drug use is 0 to 15.

\begin{tabular}{lccc}
\hline \multirow{2}{*}{ Types of drug } & \multicolumn{3}{c}{ Frequency, n (\%) } \\
\cline { 2 - 4 } Legal drugs & Mean (SD) & $\begin{array}{c}\text { Yes (sometimes/often/ } \\
\text { almost daily) }\end{array}$ \\
\cline { 2 - 4 } Alcohol & $1.18(1.87)$ & $189(75.6 \%)$ \\
Cigarettes & $61(24.4 \%)$ & $178(73.0 \%)$ \\
Illegal drugs & $69(27.0 \%)$ & \\
Class B & $2.74(1.68)$ & & $114(46.4 \%)$ \\
Cannabis & & $132(53.6 \%)$ & $2(0.8 \%)$ \\
Aerosol & & $231(99.1 \%)$ & $10(4.3 \%)$ \\
Class A & & $203(85.7 \%)$ \\
Ecstasy & & $218(92.8 \%)$ & $17(7.2 \%)$ \\
Heroin & & $227(97.4 \%)$ & $6(2.6 \%)$ \\
Crack/cocaine & & $229(98.3 \%)$ & $4(1.7 \%)$ \\
LSD & & & \\
Amphetamine & & & \\
Overall drug use & $3.85(3.09)$ & & \\
\hline
\end{tabular}

Table 3. Comparative statistics of drug use across gender, ethnic and age groups.

\begin{tabular}{|c|c|c|c|c|c|}
\hline Drug use & Group & $\mathbf{N}$ & Mean & $\begin{array}{l}\text { Standard } \\
\text { deviation }\end{array}$ & t-Value \\
\hline \multicolumn{6}{|l|}{ Gender } \\
\hline \multirow{2}{*}{ Overall } & Male & 95 & 4.15 & 3.02 & \multirow[t]{2}{*}{ n.s. } \\
\hline & Female & 136 & 3.65 & 3.17 & \\
\hline \multirow{2}{*}{ Legal drug } & Male & 108 & 2.91 & 1.71 & \multirow[t]{2}{*}{ n.s. } \\
\hline & Female & 140 & 2.61 & 1.64 & \\
\hline \multirow{2}{*}{ Illegal drug } & Male & 97 & 1.38 & 1.91 & \multirow[t]{2}{*}{ n.s. } \\
\hline & Female & 136 & 1.03 & 1.82 & \\
\hline \multicolumn{6}{|l|}{ Ethnic group } \\
\hline \multirow{2}{*}{ Overall } & White & 132 & 4.43 & 3.41 & \multirow[t]{2}{*}{$3.33 * * *$} \\
\hline & BME & 99 & 3.09 & 2.42 & \\
\hline
\end{tabular}




\begin{tabular}{cccccc}
\hline Drug use & Group & N & Mean & $\begin{array}{c}\text { Standard } \\
\text { deviation }\end{array}$ & t-Value \\
\hline \multirow{2}{*}{ Legal drug } & White & 139 & 3.02 & 1.73 & $3.04^{* *}$ \\
& BME & 99 & 2.38 & 1.54 & \\
Illegal drug & White & 133 & 1.48 & 2.19 & $2.88^{* *}$ \\
Age group (years) & BME & 100 & 0.78 & 1.21 & \\
Overall & $16-19$ & 151 & 3.89 & 3.20 & n.s. \\
\multirow{2}{*}{ Legal drug } & $20-23$ & 77 & 3.79 & 2.88 & \\
& $16-19$ & 162 & 2.69 & 1.66 & n.s. \\
Illegal drug & $20-23$ & 83 & 2.83 & 1.68 & \\
& $16-19$ & 153 & 1.29 & 2.03 & $6.86^{* *}$ \\
\hline
\end{tabular}

Note. BME $=$ Black and ethnic minority. $\mathrm{p}<.01 * * ; \mathrm{p}<.001 * * *$

\subsubsection{Risk factors related to drug use}

Table 4 presents the matrix correlations between socio-demographic characteristics, risks and protective factors. Male foster youth were more likely to be excluded from school, received less in- and post-care support from family and reported lower levels of living skills after leaving foster care as compared with females. Placement disruption among foster youth was related to self-perceived well-being, low level of living skills while in-care and low likelihood to pursue college education after leaving care. Our study also found that White foster youth were less likely to engage in post-care college education, and were more likely to be unemployed and homeless after leaving care in comparison with their minority ethnic peers. In terms of protective factors, increased likelihood of support from social service professionals and acquisition of living skills during, and post-care were not only inter-related but also associated with better outcomes among young people such as completion of college education and better self-perceived well-being. 
Table 4. Correlations between demographic characteristics, risk and protective factors.

\begin{tabular}{|c|c|c|c|c|c|c|c|c|c|c|c|c|c|c|}
\hline & & & & & & $\begin{array}{c}\mathrm{r}- \\
\text { value }\end{array}$ & & & & & & & & \\
\hline Variables & 1 & 2 & 3 & 4 & 5 & 6 & 7 & 8 & 9 & 10 & 11 & 12 & 13 & 14 \\
\hline 1. Age (years) & - & & & & & & & & & & & & & \\
\hline 2. Male & .01 & - & & & & & & & & & & & & \\
\hline 3. Ethnicity $(1,0)$ & $-.18 * *$ & -.03 & - & & & & & & & & & & & \\
\hline 4. Homelessness & .03 & -.00 & .09 & - & & & & & & & & & & \\
\hline 5. Total of placement & -.03 & -.06 & $.22 * * *$ & $.21 * * *$ & - & & & & & & & & & \\
\hline 6. School exclusion & $-.13 *$ & $.12 *$ & .10 & .07 & $.18^{* *}$ & - & & & & & & & & \\
\hline 7. Unemployment & $-.17 * *$ & .10 & .02 & $.16^{* *}$ & $.12+$ & $.12^{*}$ & - & & & & & & & \\
\hline 8. Living alone $(1,0)$ & $.11+$ & $.15^{*}$ & -.06 & -.09 & .01 & $.12+$ & -.02 & - & & & & & & \\
\hline 9. Family support (In-Care) & -.08 & $-.18 * *$ & .00 & .06 & .09 & $.14^{*}$ & -.01 & $-.12+$ & - & & & & & \\
\hline 10.Family support (After) & -.08 & $-.14 *$ & .05 & .05 & -.05 & $.17 *$ & .07 & .02 & $.32 * * *$ & - & & & & \\
\hline 11.College education $(1,0)$ & .05 & -.02 & $-.21 * *$ & $-.13 *$ & $-.23 * * *$ & -.10 & $-.28 * * *$ & -.04 & -.11 & -.10 & - & & & \\
\hline 12.Living skills (In-Care) & $-.17 * *$ & .10 & -.01 & $-.27 * * *$ & $-.22 * * *$ & -.06 & -.09 & $.18^{* *}$ & $-.12+$ & -.03 & $.18^{* * *}$ & - & & \\
\hline 13.Living skills (After) & $-.14^{*}$ & $.15^{*}$ & .07 & -.09 & $-.11+$ & -.01 & .00 & $.14 *$ & -.06 & -.02 & .02 & $.40^{* * *}$ & - & \\
\hline $\begin{array}{l}\text { 14.Professional support (In- } \\
\text { care) }\end{array}$ & $-.21 * *$ & $.11+$ & .10 & $-.16^{*}$ & -.08 & -.02 & .05 & $.12+$ & -.02 & -.02 & $.16^{*}$ & $.45^{* * *}$ & $.41 * * *$ & - \\
\hline 15.Mental Health & $-.13^{*}$ & .05 & -.05 & $-.11+$ & $-.22 * * *$ & -.06 & $-.11+$ & -.04 & .01 & .00 & .06 & $.19^{* *}$ & $.23 * * *$ & $.21 * * *$ \\
\hline
\end{tabular}

Note. $\mathrm{p}<.10+\mathrm{p}<.05^{*} ; \mathrm{p}<.01^{* *} ; \mathrm{p}<.001^{* * *}$ 
As shown in Table 5, almost all risk factors were found to be related to overall use of drug, and legal and illegal drug use among foster youth. In particular, placement disruption, school exclusion, homelessness and unemployment among young people from foster care were associated with high level of drug use. In terms of protective factors, regular support from family in-care, acquisition of living skills during care, better self-perceived well-being and completion of college education after leaving care were linked to reduced overall, legal and illegal drug use. Results also showed that foster youth who lived in transitional accommodation (that is temporary accommodation, hostels) and reported lower levels of living skills, prior to leaving care, were likely to report more frequent use of illegal drugs. Such concerns have been identified elsewhere which point to the unstable and inadequate nature of such accommodation and the greater likelihood of foster youth being exposed to a risky drug use environment (Ammerman et al., 2004, Vaughn et al., 2007)

Table 5. Correlations between risk and protective factors with drug use.

\begin{tabular}{llll}
\hline \multicolumn{1}{c}{ Variables } & \multicolumn{3}{c}{ r value } \\
\cline { 2 - 4 } & $\begin{array}{c}\text { Overall Substance } \\
\text { Abuse }\end{array}$ & $\begin{array}{c}\text { Legal Substance } \\
\text { Use }\end{array}$ & Illicit Drug Use \\
\hline Risk factors: & $.25^{* * *}$ & $.18^{* *}$ & $.29^{* * *}$ \\
1. Homelessness & $.30^{* * *}$ & $.28^{* * *}$ & $.27^{* * *}$ \\
2. Total of placement & $.34^{* * *}$ & $.25^{* * *}$ & $.30^{* * *}$ \\
3. School exclusion & $.17^{* *}$ & $.11+$ & $.16^{*}$ \\
4. Unemployment & -.09 & -.04 & $-.14^{*}$ \\
5. Living alone (1,0) & & & \\
& & & $.24^{* * *}$ \\
Protective factors: & $.23^{* * *}$ &. .03 & $.15^{*}$ \\
6. Family support (In-Care) & .01 & $-.28^{* * *}$ & -.00 \\
7. Family support (After) & $-.27^{* * *}$ & $-.16^{*}$ & $-.24^{* * *}$ \\
8. College education (1,0) & $-.22^{* * *}$ & -.05 & $-.14^{*}$ \\
9. Living skills (In-Care) & $-.14^{*}$ & .03 & $-.11+$ \\
10. Living skills (After) & -.05 & $-.14^{*}$ & $-.26^{* * *}$ \\
11.Professional support (In-care) & $-.25^{* * *}$ & & \\
12.Mental Health & & &
\end{tabular}

Note. $\mathrm{p}<.10+\mathrm{p}<.05^{*} ; \mathrm{p}<.01 * * ; \mathrm{p}<.001 * * *$

\subsubsection{Predictors of drug use, legal drug use and illegal drug use}

Table 6 presents the result of a series of hierarchical regression models that were carried out to test the relationships between risks (i.e. homelessness, total number of placements, 
school exclusion, unemployment and living alone) and protective factors (i.e. college education, in- and post-care family support, in- and post-care living skills, in-care professional support and self-perceived well-being) and current overall drug use and use of particular legal and illegal drugs among foster youth. Overall, these models were all found to be significant $(p<0.01)$ and the predictors entered into the final regression models explained a substantial portion of the variance between young people in terms of overall drug use (23\%), legal drug use $(15 \%)$ and illegal drug use (18\%). 
Table 6. Hierarchical regression analysis for variables predicting drug use, controlling for demographic variables.

\begin{tabular}{|c|c|c|c|c|c|c|c|c|c|}
\hline \multirow[b]{2}{*}{ Predictor } & \multicolumn{3}{|c|}{ Overall Substance Abuse, B } & \multicolumn{3}{|c|}{ Legal Substance Use , B } & \multicolumn{3}{|c|}{ Illicit Drugs Use, B } \\
\hline & Model 1 & Model 2 & Model 3 & Model 1 & Model 2 & Model 3 & Model 1 & Model 2 & Model 3 \\
\hline \multicolumn{10}{|l|}{ Model 1: Demographics } \\
\hline Age & -0.00 & -0.00 & -0.07 & 0.03 & -0.04 & 0.01 & -0.03 & -0.03 & -0.11 \\
\hline Male & $0.16+$ & $0.15+$ & $0.18 *$ & $0.16+$ & 0.14 & $0.16+$ & $0.14+$ & 0.13 & $0.16+$ \\
\hline White & $0.23 * *$ & $0.18^{*}$ & 0.13 & $0.23 * *$ & $0.20 *$ & $0.15+$ & $0.17^{*}$ & $0.14^{*}$ & 0.10 \\
\hline \multicolumn{10}{|l|}{ Model 2: Risk factors } \\
\hline Homelessness & & $0.15+$ & 0.10 & & 0.10 & 0.05 & & $0.17 *$ & 0.12 \\
\hline Total of placement & & 0.09 & -0.01 & & 0.07 & -0.01 & & 0.08 & -0.02 \\
\hline School exclusion & & $0.21 *$ & $0.18 *$ & & 0.18 & 0.14 & & $0.21 *$ & $0.19 *$ \\
\hline Unemployment & & -0.03 & -0.10 & & 0.00 & -0.06 & & -0.08 & -0.13 \\
\hline Living alone & & $-0.18 *$ & $-0.18^{*}$ & & -0.11 & -0.11 & & $-0.22 * *$ & $0.22 * *$ \\
\hline \multicolumn{10}{|l|}{ Model 3: Protective factors } \\
\hline Family support (In-Care) & & & $0.22 * *$ & & & $0.23 * *$ & & & $-0.14+$ \\
\hline Family support (After) & & & -0.04 & & & -0.04 & & & -0.04 \\
\hline College education & & & $-0.21 *$ & & & $-0.21 * *$ & & & -0.14 \\
\hline Living skills (In-Care) & & & -0.02 & & & -0.04 & & & -0.01 \\
\hline Living skills (After) & & & -0.03 & & & -0.02 & & & -0.01 \\
\hline Professional support (In-care) & & & 0.10 & & & 0.13 & & & 0.01 \\
\hline Mental Health & & & $-0.24 * *$ & & & $-0.14+$ & & & $-0.26 * *$ \\
\hline Adjusted $\mathrm{R}^{2}$ & .06 & .13 & .23 & .05 & .08 & .15 & .03 & .12 & .18 \\
\hline F-value & $3.74^{*}$ & $3.64 * * *$ & $3.78 * * *$ & $3.64 *$ & $2.45^{*}$ & $2.66^{* *}$ & $2.40+$ & $3.40 * *$ & $3.08 * * *$ \\
\hline
\end{tabular}

Note. Living alone $=1$; shared-accommodation $=0$.

Self-perceived well-being: 1 = good; 0 = not good.

College education: 1 = yes, completed college education since leaving care; $0=$ no.

Note. $\mathrm{p}<.10+\mathrm{p}<.05^{*} ; \mathrm{p}<.01 * * ; \mathrm{p}<.001 * * *$ 
Results in Model 1 showed that young people's socio-demographic characteristics added a modest contribution in variance explanation of young people's reports on their overall use of drugs $(\Delta \mathrm{R} 2=0.06)$, use of particular legal drug $(\Delta \mathrm{R} 2=0.05)$ and illegal drugs $(\Delta \mathrm{R} 2=0.03)$. It was found that ethnic group was the only unique predictor in which young people of White ethnicity tended to be more regular in current overall and specific drug use.

Controlling for youth characteristics, as shown in Model 2, risk factors related to young people's experience in foster care added a large share of variance in explaining overall drug use $(\Delta \mathrm{R} 2=0.11)$ and illegal drug use $(\Delta \mathrm{R} 2=0.12)$. In comparison, the contribution of risk factors for predicting legal drug use was only modest $(\Delta R 2=0.05)$. Young people who reported frequent exclusion from school and currently 'living in shared accommodation' (e.g. hostel) were more likely to report high levels of overall drug use. Hostel accommodation is invariably rather basic and only provides a bed and in some circumstances food. More importantly, such places can also have other vulnerable people staying there who are not former foster youth.

In addition, longer periods of homelessness, frequent school exclusion and living in 'shared accommodation' were all associated with the increased likelihood of illegal drug use among young people.

The addition of a range of protective factors to Model 3 made a significant contribution in explaining the variance of overall $(\Delta \mathrm{R} 2=0.13)$, legal $(\Delta \mathrm{R} 2=0.11)$ and illegal drug use $(\Delta \mathrm{R} 2=0.10)$ between young people. Foster youth who reported more regular overall and legal drug use perceived higher levels of support from family. College education was related to lower likelihood in overall and legal drug use among youth. Better self-reported well-being was linked to lower involvement in overall and illegal drug use as compared with poorer selfreported well-being status. In the final model for overall drug use, self-perceived well-being status was found to be the strongest predictor, followed by in-care family support, college education, and risk factors that include school exclusion and living situation. After controlling for the variation in youth characteristics, risks and protective factors, legal and illegal drug use were found to be predicted by different unique predictors. In particular, the strongest predictor for illegal drug use was self-reported perceived well-being, followed by living situation and school exclusion, while in-care family support was the strongest predictor for legal drug use, followed by college education.

It is important to note that the result from the regression analysis implies bi-directional relationships between risk and protective factors with drug use among foster care, while controlling for background characteristics. It does not imply causality in the relationships (Tabachnick \& Fidell, 2007). Thus, caution needs to be exercised in making causal inferences from the regression analysis. 


\subsection{Qualitative findings}

This section presents our qualitative findings to further enhance the survey results and shed light on the lived experiences of foster youth and drug use. In doing this, we seek to locate young people's experiences within a broader context to help make sense of their involvement in self-reported drug use.

\subsubsection{Perceptions of risk}

As discussed above, our survey findings suggest that young people who experience risk factors such as school exclusion, homelessness and living in shared accommodation are associated with more regular use of drugs. Moreover, previous literature and our own findings identify a multitude of vulnerabilities related to foster youth such as adjustment difficulties of placement instability, poor education outcomes and unemployment (see Allen, 2003, Wincup et al., 2003), which may lead to poverty, poor housing conditions or homelessness. Thus, it is not surprising, as revealed, in the narrative accounts, that young people often found themselves living in neighbourhoods which they considered to be risky and unsatisfactory. Problems of crime, drugs and violence were highlighted by our respondents (Guibord et al., 2011). Feelings of fear, isolation and marginalisation were a common experience reported by those living in hostels. Young people suggested that they were exposed to behaviours that presented a risk to their personal safety and protection;

I was living in kind of a halfway house, when I moved in, there was like five young people under 18 and two over 35 ... somebody moved out, another person moved in that had just come out of jail and they weren't really going to try to change their ways and started selling drugs from there and using my name to buy lots of equipment, and I'm blacklisted because of it. It wasn't a good place.

While living in shared accommodation such as a hostel was identified as risky, it seemed that even those in independent living experienced enormous challenges in maintaining personal safety and avoid getting in with the 'wrong crowd'. Furthermore, with high levels of policing in urban and poorer communities where such foster youth are likely to reside, there is an added risk of criminalisation, marginalisation and labelling of this group.

Downstairs in the very first flat there are drug addicts there and they drink a lot. I don't associate with them. I just keep well away. If I see them on the street, I'll say hi but I won't have a conversation. I don't like the look of them.

Given the experiences of loss and bereavement in a context of a lack of stable relationships, young people reported a need for love and affection, and for some stability in their life. Turning to drugs was described as a path to these states of being, or as a way of dealing with difficult situations. Although both young men and women are at risk of high rates of drug use and engagement in risky behaviours, our interview accounts, below, show that young women's narratives tended to reveal engagement in drug use and sexual activity:

The majority of them have ended up on drugs, prostituting, things like that. I'm not going to say I haven't ... like I've done escorting, when I was in care because of the money that you're getting, you can't live on $£ 5$ a week, I'm sorry you can't. Do you know 
what I mean? So I had to do escorting when I was actually in care, and then from that you get on the drugs and everything.

... I never took drugs like cocaine, heroin in the past. I did smoke like marijuana...for like ages. I drunk a lot of alcohol you know. I gave them both up about a year or so ago ... I was actually completely I would say sexually naïve ... I actually craved love and attention from someone, you know.

Interestingly, the theme of 'good knowledge/insight/reflective thinking' about their drug use, and why they had now ceased or reduced this was found to be recurrent in youth narratives. Young people's concerns reflected a range of anxieties including the dangers of getting into the 'wrong crowd', 'relationship difficulties', 'sexual naivety', 'loneliness' and 'stress'. These reported anxieties and concerns add weight to our survey findings which point to the precariousness and the challenges of homelessness, living in shared accommodation and school exclusion. Young people who had been excluded from school stressed the criminogenic nature of the environment of a special school in which they found themselves. Such settings were said to contain 'troublesome kids' with risky behaviours including criminal activity and drug use:

... that's where all the troublesome kids...trouble with the police, got criminal records, things like that. And it wasn't until then that I actually started getting myself into more trouble. In your break you'd go outside and kids would be smoking weed and that ... .

\subsubsection{Perceptions of protection}

Our survey findings identify several key protective factors in relation to drug use including college education, in-care family support, and self-perceived well-being. The latter point was evident in the ways in which young people reported the use of cannabis in preference to Class A drugs such as heroin and cocaine. Almost half of our sample of foster youth (over $45 \%$ ) report regular consumption of cannabis. Our qualitative narratives emphasise the use of cannabis as normative and safe, and as an important means to an end, that is, a strategy to cope with everyday problems and worries:

I tend to worry about things that it's not worth worrying about.. and it makes me want to light up ... I smoke weed, just to relax my head so that I start to think about whatever. Until when it has come up again ... smoking weed is ... making me sort of forget things.

Notably, drug use is often perceived as a coping strategy among foster youth. Importantly, however, our study shows that young people report a decline in drug use with the process of transition to adulthood. In the words of one 18 year old foster youth:

... you do find that a lot of foster children do go into drugs. I have been into drugs but not heavy ones. You feel that you should cope but you get into drugs or into fights. That's how you cope with things. And when you get older you realise that and you stop.

Although the above account suggests that drug use declines with age, it is important to note that such desistance is not automatic. Our interviews suggest that young people's lack of awareness of the dangerous effects of illegal drugs was an important concern. Although almost two-thirds of our quantitative sample reported receiving some help and advice on drugs and alcohol, it seemed that young people found themselves exposed to harmful illegal drugs, and were often ill-equipped to handle the situation. 
... but stuff like drugs I didn't really know because at one stage I went to a nightclub and there was one instance when my drink came back and I was spinning around. My friend told me later that somebody was going around putting stuff in people's drinks. I had cold sweats and I was lost. Never again.

In line with the survey findings, the importance of family and other social support is also revealed in the narratives. It is evident that young people's involvement in problematic drug use is also associated with availability of a supportive system. This can be seen as an engagement effort between vulnerable foster youth and support networks when dealing with drug issues and concerns.

Although, the contribution of engagement with social service professionals while in care on legal and illegal drug use was not significant in the quantitative analysis, the role of foster carers in raising awareness of drugs was highlighted by some young people in their narratives. Young people reported an appreciation of such help and advice:

Mostly she was telling me about crack, to be aware of it, there's a lot of young people taking it, so she told me to watch out for the friends I keep and don't take drinks or smoke something that someone gives you. She's just telling me make sure I watch what they do with it before I drink it, she used to warn me about it.

Although this is not borne out in our regression findings, young people's narrative accounts suggest the acquisition of living skills, and support/assistance from welfare professionals to be crucial in reduced drug use. Such support was described in a number of positive terms including encouragement, education, awareness, and advocacy. Help with budgeting, cooking, education, and housing was deemed to be essential in the transition from care to the community, and to adulthood. Young people reported on the challenges in maintaining their housing and dealing with the new expectations of them as emerging independent adults:

... in terms of helping me to budget and manage money and all that I didn't really have much support ... I didn't fill out certain forms for my, like tax, council tax, and the next thing I know after a year of living on my own there was like a grand's $(£ 1,000)$ worth of debt cos of not paying my rent on time. when I was younger like, when bills just come through the door you're just thinking like 'Yeah yeah, they'll go away' and just put it in a drawer, and then they just pile up, pile up, and you could lose your place, and it was real hectic ... .

The young person in the above quote reported that although he lost his flat, another social worker that was allocated to him subsequently fought hard for him to get it back. Such accounts demonstrate the protective aspects embedded in formal support which prevents risky situations from developing and deteriorating.

\section{Discussion}

Our study reveals a complex picture of drug use among foster youth that reflects their difficult experiences of the foster care system. Our findings suggest that drug use, including illegal drugs, is a significant phenomenon in the lives of foster youth. This finding is in accordance with previous research evidence that has recorded risk of drug use/misuse pattern 
among foster youth and those involved with child welfare services (see Aarons et al., 2001, Slesnick and Meade, 2001, Vaughn et al., 2007).

Current findings indicate linkage between youth characteristics and involvement of drug use. Our survey findings confirm previous research which suggests that White youth are more likely than minority ethnic youth to report drug use (Vaughn et al., 2007). Moreover, our findings of an insignificant association between age and drug use are inconsistent with previous studies of drug use with samples of youth in out-of-home placements (Guibord et al., 2011, Hammersley et al., 2003). These studies' sample ranged in age from 12 to 15 years, whereas the present sample comprised youth aged 16-23. Nonetheless, in line with Ward et al. (2003), we argue that drugs are a part of the complex web of challenges faced by foster youth in the process of transition from care to independence. Also, those foster care youth who are using illegal drugs, and report a high use of legal drugs may have greater likelihood of misuse/dependence issues, as opposed to experimental or recreational use. Our findings suggest a crucial need for appropriate and targeted education and awareness, and other focused intervention policy/practice to work towards desistance (Barry, 2006, Barry, 2013).

We found that key risk factors including experience of homelessness, school exclusion and living setting were strong influences that predict high levels of drug use among foster youth.

Our study presents evidence that more frequent school exclusion, longer periods of homelessness after leaving care, and current living setting correlated with both legal and illegal drug use. Previous research has consistently reported poor levels of educational attainment and low probability of school completion among this group when compared with their peers in the community (Courtney and Dworsky, 2006, Courtney et al., 2007, Stein, 2006). Crucially, a lack of education qualifications hinders the efforts of these young people to secure stable employment, which can lead to financial difficulties and episodes of homelessness (Buehler et al., 2000, Stein, 2006). Arguably, stressful life events such as chronic unemployment, poverty and homelessness help explain the high rates of self-reported use of legal and illegal drugs among our group of foster youth (Wincup et al., 2003).

In line with some previous research, our quantitative and qualitative findings indicate that foster youth in shared living accommodation are at greater risk of drug use (Vaughn et al., 2007). Young people's narratives reveal that a shared housing context is more exposed to risks of drug use, including illegal drugs. One plausible explanation is that shared accommodation which may mirror a residential care environment, has been described as a 'hostel culture' exposing youth to negative peer attitudes/relationships (Ammerman et al., 2004) and is also associated with increased problematic behaviours among youth (Biehal et al., 1995). We found that although there were existing transitional living programmes, some youth may not utilise available assistance that could provide them a place to live for a successful transition (Garrett et al., 2008). This could further expose former foster youth to homelessness or situations where they often stay with peers experiencing difficult circumstance themselves and may exacerbate negative living situations (Ammerman et al., 2004). These negative circumstances associated with shared living settings may amplify the probability of youth experiencing negative outcomes; while, independent living setting may protect foster youth against involvement in problematic risk-taking, such as heavy and persistence drug use. 
Young people's accounts also suggest the need for 'love and attention', and indicate engagement in sexual activity including 'escorting', and 'prostitution'. Such narratives are supported by recent high profile inquiries in the UK which identify a strong link between drug use and sexual exploitation of young people in foster care, and suggest vulnerability and exposure to risk (Berelowitz et al., 2012, Jay, 2014).

Findings also revealed that the protective factors included in the quantitative analyses have lower likelihood in mitigating problematic behaviour of drug use among foster youth, after controlling for the effects of risk factors. However, while quantitative findings revealed substantial contribution of risk factors in predicting foster youth drug use, the role of protective factors that include supportive family support, better education attainment and well-being should not be underestimated. Contrary to expectation, the study reveals a positive association between family support networks during care and involvement in drug use. However, it should also be noted that the significant contribution of family support in care and illegal drug use was not confirmed. Past research has often asserted that the lack of positive family support (Reilly, 2003) and inability to build lasting relationships due to disruptive placements (Biehal et al., 1995) reduce the likelihood of a positive transition to adulthood. While helping birth parents to re-establish bonding could reduce young people's drug use, Cheng and Lo (2011) have argued that inadequate supervision/affectional bonds of birth parents could pose lingering negative impacts on young people's development, including drug use. This may explain the current finding on the association between regular contact with birth family members and greater drug use among former foster youth. Having said that, the result from regression analysis does not imply that the relationship between family support networks and drug use is causal. Thus, this finding may also suggest that foster youth who are involved in drug misuse also have a greater access to support provided by family members. This could be seen as a coping strategy for youth to deal with their involvement in drug misuse.

Drawing from literature on foster youth, our study reveals significant buffering effects of attainment of college education after care and good self-perceived well-being on drug use among foster youth. Literature has identified that young people with emotional and behavioural disorder, and those living in state care are at an increased risk and are vulnerable to drug misuse (Advisory Council on the Misuse of Drugs, 2006, McCrystal et al., 2008). Specifically, youth with post-traumatic stress disorder (PTSD) and conduct disorder (CD) have been found to have higher rates of drug use and disorder, with strong relations found between being diagnosed with CD and both legal and illegal drug use and disorder, current and lifetime (Vaughn et al., 2007).

Our findings also suggest that young people who progress to further education after leaving care tend to report lower rates of drug use compared with those who do not. Some researchers have highlighted that adverse pre-care experience and characteristics (i.e. educational and behavioural difficulties) of foster youth may disadvantage them educationally (Sinclair \& Gibbs, 1998) and that poor educational outcomes may be due to features of the care home and negative views of social workers (St Claire \& Osborne, 1987). Others have argued that positive education attainment is proven to promote opportunities to develop out-of-school interests (Martin \& Jackson, 2002) and subsequently, buffer against foster youth involvement in negative outcomes such as risky drug use behaviour (Allen, 2003). Moreover, foster youth's progress in education is closely linked to a higher commitment to their educational success and 
continuous support from carers and teachers (Shaw, 1998) and these contribute to higher likelihood of young people to be maintained in school at a later stage (Martin \& Jackson, 2002).

\subsection{Limitations}

While the present study makes an important contribution to our understanding of risk and protective factors, it has several limitations. First, the survey and interview data are based on self-reported activity, which could have resulted in over- or under-reporting of drug use. Data are also gathered from a self-selected sample, which can lead to bias as participants may not be representative of the entire target population (Lavrakas, 2008). Secondly, legal and illegal drug use was only measured during the last 30 days, not currently and lifetime. Thirdly, the fact that the data were not derived from a longitudinal sample further limits the ability to make causal inferences. Finally, as the study sample is only drawn from England, the findings of this study may not be generalisable to foster youth in other parts of the United Kingdom, or elsewhere. Findings from the current study only focus on young people who had been in care and lacks comparison with a non-foster youth population. In addition, the non-probability techniques employed and $20 \%$ to $50 \%$ response range per agency in this study limits generalisability. However, past scholars have noted that a sample of higher risk youth is not amenable to conventional techniques, and findings derived are crucial for exploring whether certain relationships should be revisited and verified in the future (Baron, 2006). Despite these limitations, this study adds important knowledge to the area of drug use within the child welfare arena and in particular, foster youth in the United Kingdom state care system, interview narratives provide a rich account of young people's perceptions about risk, vulnerability and support. Notably, although the interview group suffers from the limitation of being selfselecting and the inevitable bias inherent in this, the qualitative narratives paint a nuanced picture that helps promote understanding of their context and surroundings to appreciate difficulties and challenges faced by foster youth transitioning from foster care and into adulthood.

\section{Conclusion}

The paper points to the need to understand the unique influence of risk and protective factors for involvement in drug use among youth in and leaving foster care. Findings from the survey and interviews with foster youth point to the importance of pre-leaving care support that includes preventing school exclusion, promoting opportunities for further education, enhancing well-being and, creating supportive and bonding relationships between carers and young people. Specifically, opportunities for further education such as continuous support from carers and teachers in developing out-of-school interests could help foster youth to engage in education at a later stage. Moreover, interventions that target appropriate behavioural and emotional difficulties (i.e. conduct disorder, traumatic experience prior to entering care, distress pre- and post-care, adjustment in care home) is crucial to protect against risks of school exclusion, and promote mental well-being of these vulnerable youths. Accommodation, in particular an independent living setting, is very important as a key for foster youth to experience a more positive transition to adulthood and integration into community. Crucially, the supportive relationship between foster youth and professional support workers which develops through a persistent and consistent approach, is of vital importance. Accommodation, in particular an independent living setting, is very important as a key to obviate foster youth from 
getting involved in drugs or reduce likelihood of escalation to illegal drug use so that foster youth may experience a more positive transition to adulthood and integration into community.

\section{Acknowledgement}

This study was funded by a grant from the Joseph Rowntree Foundation. The study would not have been possible without the participation of foster youth who, very kindly, agreed to share their experiences with us. We are grateful to them for their invaluable input. Special thanks also go out to the reviewers for their helpful comments in the revision of this paper.

\section{Reference}

Aarons G.A., Brown S.A., Hough R.L., Garland A.F. and Wood P.A., Prevalence of substance use disorders across five sectors of care, Journal of the American Academy of Child and Adolescent Psychiatry 40, 2001, 419-426.

Aarons G.A., Hazen A.L., Leslie L.K., Hough R.L., Monn A.R., Connelly C.D., et al., Substance involvement among youths in child welfare: The role of common and unique risk factors, American Journal of Orthopsychiatry 78 (3), 2008, 340-349.

Advisory Council on the Misuse of Drugs, Pathways of problems. Hazardous use of tobacco, alcohol and other drugs by young people in the UK and its implications for policy, 2006, Advisory Council on the Misuse of Drugs; London.

Allen M., Into the mainstream: Care leavers entering work, education and training, 2003, Joseph Rowntree Foundation; North Yorkshire.

Ammerman S.D., Ensign J., Kirzner R., Meininger E.T., Tornabene M., Warf C.W., et al., Homeless young adults" ages: Examining service delivery adaptations, 2004, National Health Care for the Homeless Council, Inc.; Nashville, 18-24.

Barn R., Care leavers and social capital: Understanding and negotiating racial and ethnic identity, Ethnic and Racial Studies 33 (5), 2010, 832-850.

Barn R., Andrew L. and Mantovani N., Life after care: The experiences of young people from different ethnic groups, 2005, Joseph Rowntree Foundation.

Barn R. and Mantovani N., Young mothers and the care system: Contextualizing risk and vulnerability, British Journal of Social Work 37 (2), 2007, 225-243.

Barn R. and Tan J.P., Foster youth and crime: Employing general strain theory to promote understanding, Journal of Criminal Justice 40 (3), 2012, 212-220.

Baron S., Street youth, strain theory and crime, Journal of Criminal Justice 34, 2006, 209223.

Barry M., Youth offending in transition: The search for social recognition, 2006, Routledge; Abingdon.

Barry M., Desistance by design: Offenders' reflections on criminal justice theory, policy and practice, European Journal of Probation 5 (2), 2013, 47-65. 
Barth R., On their own: The experiences of youth after foster care, Child and Adolescent Social Work 7, 1990, 419-440.

Berelowitz S., Firmin C., Edwards M.G. and Gulyurtlu S., I thought I was the only one. The only one in the world, The Office of the Children's Commissioner's inquiry into child sexual exploitation in gangs and groups: Interim report, 2012,

The Office of the Children"s Commissioner in England; London.

Biehal N., Clayden J., Stein M. and Wade J., Moving on: Young people and leaving care schemes, 1995, HMSO; London.

Braciszewski J.M., Moore R.S. and Stout R.L., Rationale for a new direction in foster youth substance use disorder prevention, Journal of Substance Use 19 (1-2), 2014, 108-111.

Broad B., Young people leaving care: Life after the Children Act 1989, 1998, Jessica Kingsley; London.

Buehler C., Orme J.G., Post J. and Patterson S.A., The long-term correlates of family foster care, Children and Youth Services Review 22 (8), 2000, 595-625.

Chase E., Maxwell C., Knight A. and Aggleton P., Pregnancy and parenthood among young people in and leaving care: What are the influencing factors, and what makes a difference in providing support?, Journal of Adolescence 29 (3), 2006,

$437-451$.

Cheng, T. C., \& Lo, C. C., A longitudinal analysis of some risk and protective factors in marijuana use by adolescents receiving child welfare services. Children and Youth Services Review, 33(9), 2011, 1667-1672.

Courtney M.E. and Dworsky A., Early outcomes for young adults transitioning from out-ofhome care in the U.S.A., Child and Family Social Work 11, 2006, 209-219.

Courtney M.E., Dworsky A., Brown A., Cary C., Love K., Vorhies V., et al., Midwest evaluation of the adult functioning of former foster youth: Outcomes at age 26, 2011, Chapin Hall Center for Children at the University of Chicago; Chicago, IL.

Courtney M.E., Dworsky A., Cusick G., Havlicek J., Perez A. and Keller T., Midwest evaluation of the adult functioning of former foster youth: Outcomes at age 21, 2007, Chapin Hall Centre for Children at the University of Chicago; Chicago.

Darker I., Ward H. and Caulfield L., An analysis of offending by young people looked after by local authorities, Youth justice 8 (2), 2008, 134-148.

Del Valle, J. F., López, M., Montserrat, C., \& Bravo, A., Twenty years of foster care in Spain: Profiles, patterns and outcomes. Children and Youth Services Review, 31(8), 2009, 847-853.

Dennis M.L., White M.K. and Ives M.L., Individual characteristics and needs associated with substance misuse of adolescents and young adults in addiction treatment, Adolescent Substance Abuse 9 (1), 2009, 45-72.

Feng C., DeBeck K., Kerr T., Mathias S., Montaner J. and Wood E., Homelessness independently predicts injection drug use initiation among street-involved youth in a Canadian setting, Journal of Adolescent Health 52, 2013, 499-501. 
Garrett S.B., Higo D.H., Phares M.M., Peterson P.L., Wells E.A. and Baer J.S., Homeless youths" perceptions of services and transitions to stable housing, Evaluation and Program Planning 31 (4), 2008, 436-444.

Guibord M., Bell T., Romano E. and Rouillard L., Risk and protective factors for depression and substance use in an adolescent child welfare sample, Children and Youth Services Review 33, 2011, 2127-2137.

Hammersley R., Marsland L. and Reid M., Substance use by young offenders: The impact of the normalisation of drug use in the early years of the 21 st century, Home Office Research Series 261 2003, Home Office Research, Development and Statistics; London.

Hass M. and Graydon K., Sources of resiliency among successful foster youth, Children and Youth Services Review 31 (4), 2009, 457-463.

Havlicek J.R., Garcia A.R. and Smith D.C., Mental health and substance use disorders among foster youth transitioning to adulthood: Past research and future directions, Children and Youth Services Review 35 (1), 2013, 194-203.

Helstrom A., Bryan A., Hutchison K.E., Riggs P.D. and Blechman E.A., Tobacco and alcohol use as an explanation for the association between externalizing behavior and illicit drug use among delinquent adolescents, Prevention Science 5 (4),

2004, 267-277.

Henkel D., Unemployment and substance use: A review of the literature (1990-2010), Current Drug Abuse Reviews 4 (1), 2011, 4-27.

Iglehart A.P., Adolescents in foster care: Predicting behavioral maladjustment, Child and Adolescent Social Work Journal 10 (6), 1993, 521-532.

Jackson S. and Simon A., The costs and benefits of educating children in care, In: Chase E., Simon A. and Jackson S., (Eds.), Care and after: A positive perspective, 2005, Routledge; London, 44-62.

Jarrett, R. L., Growing up poor: The family experiences of socially mobile youth in lowincome African American neighborhoods. Journal of Adolescent Research, 10(1), $1995,111-135$.

Jay A., Independent inquiry into child sexual exploitation in Rotherham 1997-2013, 2014, Rotherham Metropolitan Borough Council; Rotherham.

Lavrakas P.J., Encyclopedia of Survey Research Methods Vol.1, 2008, Sage Publications.

Legault L., Anawati M. and Flynn R., Factors favoring psychological resilience among fostered young people, Children and Youth Services Review 28, 2006, 1024-1038.

Martin P.Y. and Jackson S., Educational success for children in public care: Advice from a group of high achievers, Child and Family Social Work 7, 2002, 121-130.

Masten A.S. and Reed M.J., Resilience in development, In: Lopez S. and Snyder C., (Eds.), Handbook of positive psychology, 2002, Oxford University Press; New York, 74-88.

McCrystal P., Percy A. and Higgins K., Substance use among young people living in residential state care, Child Care in Practice 14 (2), 2008, 181-192. 
Mendes P. and Moslehuddin B., From dependence to interdependence: Towards better outcomes for young people leaving state care, Child Abuse Review 15, 2006, 110-126.

Monaghan M., Drug policy governance in the UK: Lessons from changes to and debates concerning the classification of cannabis under the 1971 Misuse of Drugs Act, International Journal of Drug Policy 25 (5), 2014, 1025-1030.

Reilly T., Transition from care: Status and outcomes of youth who age out of foster care, Child Welfare 32 (6), 2003, 722-746.

Ritchie J. and Spencer L., Qualitative data analysis for applied policy research', In: Bryman Alan and Burgess Robert G., (Eds.), Analysing qualitative data, 1994, Routledge, 173194.

Shaw C., Remember my messages. Who cares?, 1998, London; Trust.

Sinclair I. and Gibbs I., Children"s homes: A study in diversity, 1998, Wiley; London.

Slesnick N. and Meade M., System youth: A subgroup of substance-abusing homeless adolescents, Journal of Substance Abuse 13, 2001, 367-384.

St Claire L. and Osborne A.F., The ability and behaviour of children who are 'in care' or separated from their parents, Early Child Development and Care 28, 1987, 187-354.

Stein M., Young people aging out of care: The poverty of theory, Children and Youth Services Review 28, 2006, 422-434.

Stice E., Kirz J. and Borbely C., Disentangling adolescent substance use and problem use within a clinical sample, Journal of Adolescent Research 17 (2), 2002, 122-142.

Tabachnick B.G. and Fidell L.S., Using multivariate statistics, fifth ed., 2007, Allyn \& Bacon; Boston.

Taylor C., Young people in care and criminal behaviour, 2006, Jessica Kingsley; London.

Vaughn M.G., Ollie M.T., McMillen J.C., Scott L. and Munson M., Substance use and abuse among older youth in foster care, Addictive Behaviors 32 (9), 2007, 1929-1935.

Wade JJ., Leaving care, Quality protects research briefing, 7, Dartington, Department of Health/Research in Practice/Making Research Count, 2003.

Wall A.E. and Kohl P.L., Substance use in maltreated youth: Findings from the national survey of child and adolescent well-being, Child Maltreatment 12, 2007, 20-30.

Ward J., Henderson Z. and Pearson G., One problem among many: Drug use among care leavers in transition to independent living, Home office research study no. 260, 2003, Home Office; London.

Wincup E., Buckland G. and Bayliss R., Youth homelessness and substance use: Report to the Drugs and Alcohol Research Unit, Home office research study no. 258, 2003, Home Office; London. 